\title{
The gerontological design: a practice to improve life quality of the elderly
}

\begin{abstract}
The gerontological design is recognized like a specific field of the design that links the gerontology to respond effectively to the adaptation process of the elderly, applying an integral vision that join functional and Psychoemotional needs. So this field stablishes the chance to educate to the industrial designers in the The National University of Colombia, like proficient professionals and socially responsible in pursuit of the institutional mission
\end{abstract}

Method: As part of the academic activity made in the Project made design and use subject of the industrial design program of the National University of Colombia, it's develop the project "Application of the gerontological design and ergonomics in the products development.

Results: An object system prototype was made, developed to strengthen and maintain the visual, motor and auditory capacities, in which design process was prioritized the elderly participation.

Objective: Submit an academic experience that links the research in the formative processes, through the object system design that helps the development of the daily life of the elderly.

Conclusion: From the perspective of the project, the industrial design promotes the integral qualification of users in situations of physical or cognitive disability, seeking the improvement of their quality of life through the research and a proposal of implemented alternatives in objects and products whose purpose is decrease the difficulties that arise in the rehabilitation process and support the work of the professionals in charge of providing health and educational services. Also the development of these projects, enable the social inclusion and a better performance of the users.

Keywords: Gerontological design, elderly, inclusive design, ergonomics
Volume 5 Issue 4 - 2018

\author{
Gloria Patricia Herrera Saray, Eliana Castro \\ Silva \\ Industrial Designer, Associate Professor, National University of \\ Colombia, Colombia
}

Correspondence: Eliana Castro Silva, Industrial Designer, Associate Professor, National University of Colombia, Colombia, Email ecastros@unal.edu.co

Received: July 04, 2017 | Published: July 10, 2018

\section{Introduction}

Today, many persons aspire to live until the 60 years old. The greatest life expectancy, added to the important drop in the birth rate, is the cause of the fastest ageing of the population of the world. ${ }^{1}$ According to Mision Colombia envejece (Mission Colombia grows old), a research between Fedesarrollo and the Saldarriaga Concha Fundation made in 2015 in the paper: the process of the aging of society in Colombia 1985-2050, those over 60 years old, who today are 10 percent will reach the 24 percent in 2050.According to the research, currently the people over 60 years old don't overcome the 10 percent of population. The people over 80 years old achieve the 700.000 people. But in 35 years the people over 60 years old almost will be triple.

In addition to this, life expectancy at birth continues to increase. While in 1990, was of 65 years old for men and 72 years old for women, for the 2050 it will be 78 for men and 83 for women. In addition to the above the number of disabled elderly continue increasing today, particularly between cohort "Baby boom". ${ }^{2}$ The faster growth of the population ageing makes indispensable maximize the adaptability of people to their progressive physical and/or mental deterioration; and this necessarily shall be accompanied of the adapting of the immediate environment. Including objects of the daily life and the urban condition. The implementation of the design and ergonomics to improvement of the spaces (furniture, everyday objects, and technical aids), realization of safe habits and preventive behaviors, will allow to more elderly and people with disabilities to aging in their own context improving their quality of life instead of require many persons in their family or move to retirement or nursing homes to satisfy their basic needs. In turn will be attributed to reduce the dangers in the daily activities that could cause disabilities, the rapid evolution of that disability and fragility as well as exalt autonomy, wellness and safety feelings reducing health care costs.

Progressively the objects and the spaces, where the elderly and people with disabilities develop their daily life activities, are losing their use properties because they do not correspond with the real features from this population and least of all when this people have any kind of physical or cognitive alteration. The above produce gradually a reduction in the quality of life of the elderly, that usually impact in depression, decline in physical activity and increase of diseases. Thus, when are projecting objects and spaces aimed at this type of users, it need to think in depth about the analysis of the usability, habitability and accessibility criteria to carry out activities of daily living reducing their dependence and increase the quality of life. 
The designers are able to modify, transform and generate the field in search of various user requirements. The objective is improve the quality of life of the people within a framework of most basics human rights. The industrial designer is responsible for $70 \%$ to $80 \%$ what its happens a product throughout its life. ${ }^{3}$ To carry out his duties, the designer must be aware of the changes of the socio-demographic changes that the world presents. The main one is the aging of the global population and the near context. This factor is important because according to the as people get older, they need products and services according to their mental and physical features that help to carry out their daily activities and not be excluded from society.

All of the above is framed in what is called: socially responsible design which is a global and integral position to include all those involved in the actions, as well as it natural and artificial environment. ${ }^{4}$ It is allowing to the people with disabilities, and elderly equal opportunities to develop their capacities through support objects, offering safety of the time to use the product; offering a product that suits to its condition, allowing the participation inside the design process; developing accessible products.

At The National University of Colombia the social responsibility, is base in the document Mission in which says "The The National University of Colombia promotes equal access to the Colombian education system; it provides the largest offering of academic programs and trains competent and socially responsible professionals. It contributes to the development and re-significance of the Nation project; it studies and enriches the cultural, natural and environmental country's heritage. As it, assists to the scientific, technological, cultural and artistic order, with academic and research autonomy"

Consequently we consider from the industrial design, the social responsibility it cannot be interpreted just in strategic and market term, otherwise in the social and equity sense, with coherent, creative and relevant responses with the communities which manage their efforts. Gamonal says. ${ }^{5}$ The designer not only has the responsibility as individual or citizen, otherwise signature, text and speech producer in form of design that will be installed in society and most strongly, they will take part in the triad connection person-object-environment.

So the design has been a socially responsible activity, the framework of Project node design and use subject of the industrial design program of the The National University of Colombia Palmira campus, the ergonomics and sustainability research group through the line of social inclusion and citizen construction proposes two projects: "designing for disability" and "Application of the gerontological design and ergonomics in the product's development" both projects framed in the social aspect of design which allow to know to the student the current scene of the demographic transition of the aging and the disability, its consequences in the different fields of the society which become in chances to do the proposal which helps to improve their quality of life, allowing their inclusion, safety and autonomy, this is one of biggest challenge for the future professionals of the industrial design.

\section{Case report}

The present paper emerges from various requirements in the development of the activities that People with disabilities can do (especially who suffer chronic degenerative diseases that involves pain and/or elderly this situation is consider like a big challenge for the public health, dangerous and expensive both for the user and his family. The attention requirements are every time more important and the isolation to which users are subjected because of their inabilities to do basic activities of the daily life. The physical, mental and social disabilities closely related to the increase of life expectancy are considered in the most serious problems to face in the XXI century. This is not just a health problem, the designers and architects are called to solve much of the needs that they have. These professions have a great meaning and importance in the elderly and people with disabilities situation.

As a consequence, in the framework of Project node design and use subject of the industrial design program of the The National University of Colombia , Palmira campus, the ergonomics and sustainability research group through the line of social inclusion and citizen construction proposes one of its general projects: "Application of the gerontological design and ergonomics in the product's development".

The project is framing in the social aspect of the design having as biannual goal, first of all, establish design standard with ergonomics basis in accordance with the features of this sector of the population to improve the usefulness from the current products. In the second instance give design proposal (prototypes) to do the activities of the daily life, that conduct to the improvement of it usability and optimization of the quality of life of the user. Consequently, is possible to include within the education of the future professional of Industrial Design certain topics that tend to the understanding of the reality of our context.

The accomplishment of these projects is achieved because the investigation group was winner in National Call Of Projects To Promotion Or The Research, Creation And Innovation Of The National University Of Colombia 2016-2018, this call is for research projects.

The case report is called "Do-Re Mayor. Trayendo melodias de la memoria" (Do-Re Mayor. Bringing melodies to the memory) was developed for the nursing home located in Palmira Valle, where the students did their field work.

User age range: Between 70 years old and 80 years old. Predominant feature: Limitations on upper and lower limb mobility. Residual capacities: pincer grasp, shapes and colors recognition and sounds identification, sensory deficit (hearing and vision) chronic and degenerative illness, appearance of demential and cognitive disruption-scholar level: none, elementary, high school. Condition: Some users had been carry to the nursing home for their family, many others are in neglect condition. Psychological feature: fear. Functional rehabilitation-loss of social, family and working role- lack of motivation to do group activities.

The main objective of the project was the maintenance of the residual capacities of fine and gross motor of their extremities superior through by the execution and recognition of sounds and melodies of his time through a design proposal that motivate to the user to listen, run and make sounds by the group use of musical part in his life. The previous, called reminiscence therapy: which aims encourage by the memories. The group reminiscence promotes the socialization, relaxation and Self-knowledge. ${ }^{6}$ The Project Do-Re Mayor. Trayendo Melodías De La Memoria" (Do-Re Mayor. Bringing melodies to the memory) has as a main feature: the evocation of memories and events from the past of the person, connect it with the present through the sounds, and encouraging past experience expression as 
well as capacity of Self-knowledge. The above helps to the patient to improve, maintain and restore a well-being condition, mobility and vision aspect of the elderly through the sound.

Due the above is achieved the research from an investigation diagram through the application of the ergonomics. From the first stage of the process it worked with the oldest user, it that is called: participatory design. The student in his exploratory research must advise with therapist who give the basis related with physiological of the user, on the other hand is fundamental the research of the space where in getting on the user in his daily life and the elements to use for his therapy, in this case elements that involves activation for the sound creation. In short, the research of habitability and Usability of the space and objects of his daily use for the identification of real needs of the user and the caregiver (Figure 1). It was identified that the users manifested monotony, little motivation for the movement, just they made the exercises with the therapist and some persons interacted with board game, manifested to remember a lot music from their time and their sounds of the pacific region. After this period of needs identification, they make research corresponding to the design of current solutions that are found in the market for the answer of these needs, the evaluation and proposal of requirements is performed that all the proposals must have and give solutions to the anomalies identified. In such a way that the final proposal produce physical and emotional answers to the users (Figure 2).

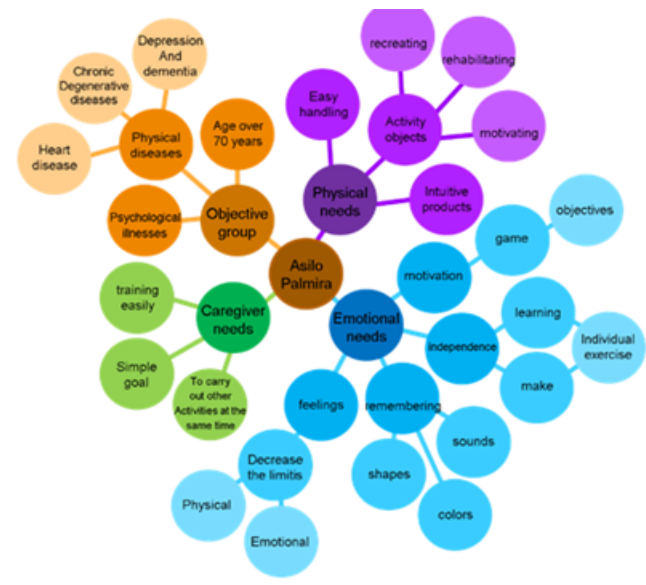

Figure I General analysis of actual condition of the needs of elderly and the caregiver.

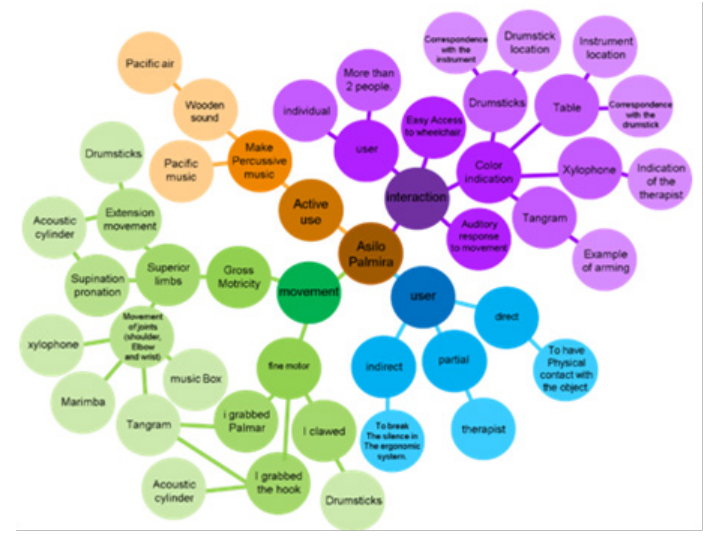

Figure 2 Design requirements.

\section{Design physical requirements}

Stimulation of fine and gross motor through the creation of movements to produce percussion at the systems.

\section{Accessibility requirements}

facilitating the accessibility of users in wheelchairs, in conventional chairs and in bipedal position.

\section{Psychological requirements}

Encouraging the autonomy, communication, the relation with others, material implementation and elements that produce sounds of pacific music that promotes the reminiscence of the pacific music, familiar sounds, and color identification.

\section{Biomechanical requirements}

Promoting the generation of extension, supination and pronation movements through the performance of percussion of the subsystems. The next step is the development of the simulators of functional models which are systems of anthropometric and biomechanical testing that make easier the decision making regarding usability.

The users gave their opinions with respect to the size, use and produce sounds (Figure 3).

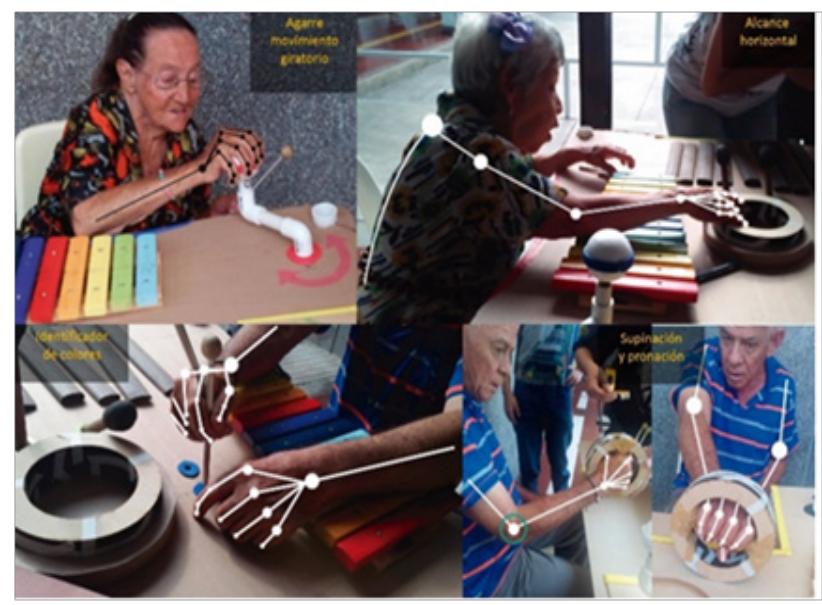

Figure 3 Biomechanical analysis made to the different subsystems.

As a general conclusion and with user inputs it was determinate to do a musical table that involves pacific sounds, a big system compound for 4 subsystems of percussion instrument where is produce through the activation of sounds. The system is a musical board compound for the subsystems (Figure 4) (Figure 5).
i. Marimba
ii. Xylophone
iii. Acoustic drawer
iv. Rain ring

Also 2 subsystems to encourage the movement and the memory:
i. Tangram
ii. Rotating levers 


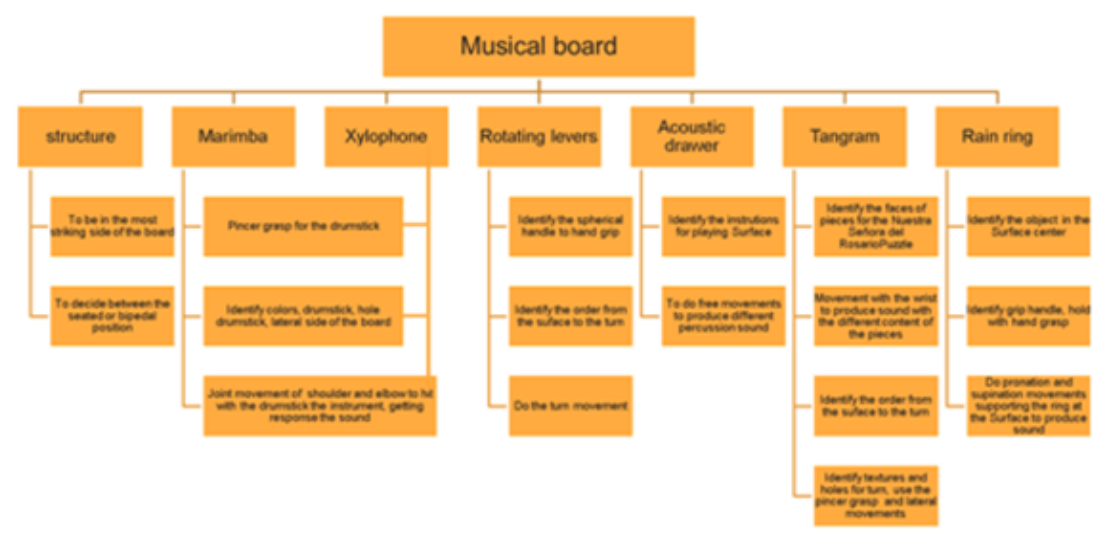

Figure 4 the system is a musical board compound for subsystems that active, making interaction with other users.
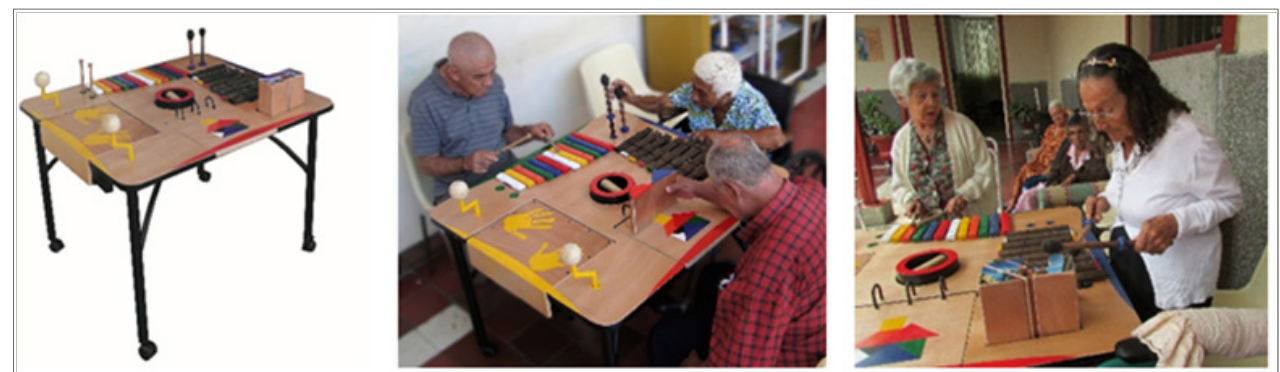

Figure 5 "Do-Re Mayor.Trayendo melodías de la memoria" (Do-Re Mayor. bringing melodies to the memory)" Evocationing of the memories and events from the past connecting to the user with the present through the pacific sounds and stimulating the expression of past experiences.

\section{Final product}

Do-Re Mayor Trayendo melodías de la memoria" (Do-Re Mayor. Bringing melodies to the memory) is a project that search maintain, improve and rehabilitate through the music and social integration. This allow the cognitive stimulation through the different musical parts. Which are percussion instruments that assist with the remembrance of sounds and memories of yesterday. The above is achieved through:

Sensory stimulation: The table have different color, texture and sounds that contribute to improve, maintain or reduces the deterioration of mobility and vision coordination.

Fine motor skills: Allowing to exercise the upper extremities and phalanges with movements as pincer grasp, hand grip and hook grab.

Gross motor skills: Allowing to exercise the upper extremities with dynamic stretches for the ranges accompanied by movements of supination and pronation.

Memory exercise: Stimulating and keeping the brain active and the memory awaken that search maintain, improve and rehabilitate and reduce the decline of the cognitive functioning.

Social Component: facilitating the communication through exercises for the activity for cognitive improvement, with improvement to the language, attention and concentration through the socialization and work team (Figure 6).

The projects made in this call were donated to the Palmira nursing home, there these will be proven. Some of these projects are restart as degree project for the students in this way it seeks to perfect the design proposal with the contribution made by the users. The inclusion of the user and the interdisciplinary work in the entire design process from the first ideas, through the simulation process to the final prototype ensures a greater functionality of the product.

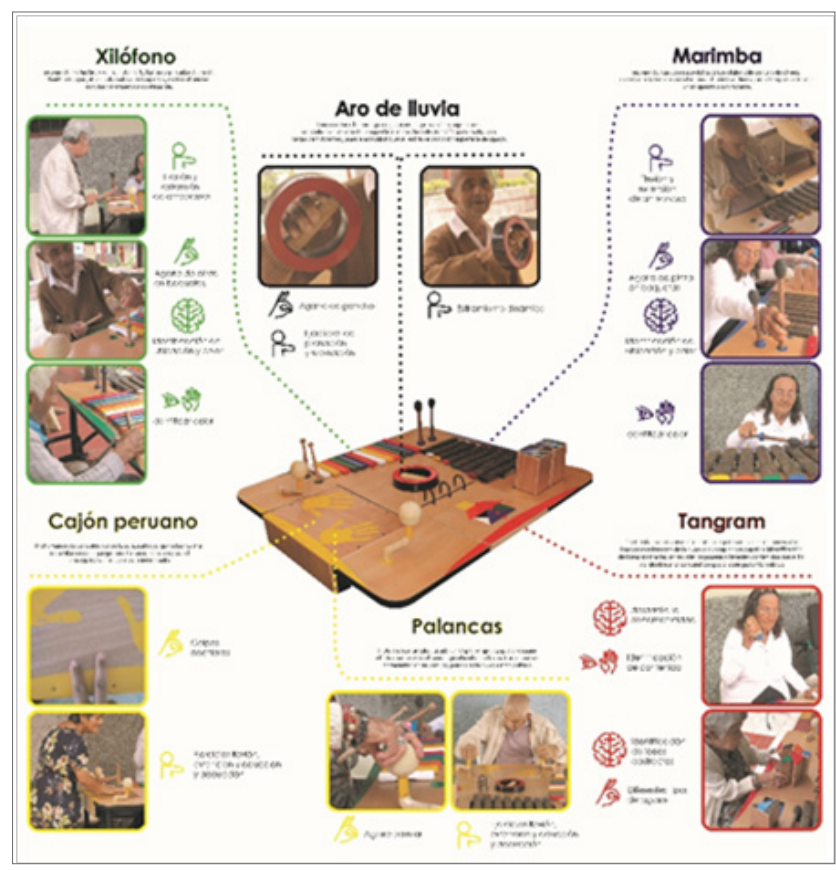

Figure 6 Musical board in fographic Do-Re Mayor. 


\section{Discussion}

The world of disability and old age is a space still few explored by the Latin-American designer and architect. This is how the approach of design for disability and solutions for the old age, makes it necessary the re-definition of different process, widely used approach methodology, because they had been built around the concept of kind of user. In accordance with the above, the design to disability and old age require lots of information about the human factors and how these are related with the activity to do and the environment, the ergonomics of the specific needs is responsible for this. The ergonomics with the support of ergonomics theories as the accessibility and the usability, the habitability sideways the inclusive design are presented as propositional entities since the design made the activity in favor of the quality of life, they had taken the responsibility implementing methodologies for the space and objects generation that make easier these process. They are consolidated as main focus of the pooled work that have objective, to satisfy the needs of wider range of user design and ergonomics for the disability and the elderly.

Kirkwood $^{7}$ says that the process of aging is very influenced by the effects of the surrounding states, the lifestyle and the illness and they are related with the aging or change for its cause, but they are not for the aging. The gerontological design join the gerontology with the design to project, conceive and adapt models for the older adults and avoiding that, maliciously the people sell models designed for people with failure. ${ }^{8}$ The world design focus in the older adults or gerontological design cover the design of all everyday objects. It is time to observe to the people and to realize that needs are changing. The importance of the gerontological design lives in the gradual increase in population of older adults because according to the Red Latinoamericana de Investigación Del envejecimiento (Latin American Network for Research on Aging) one person of 6 will be over 60 years old in 2030 year. $^{9}$

An important aspect of the gerontological design is no just focus in resolve problems with products and services only functional, take into account the psycho-emotional needs of the older people, aspects that in the process of design are fundamental for the success of the final product. In the design process, the users participate are understood as all the persons that are related with the product: manufacturer, caregiver, final users, experts, etc. have its relevance in the definition and validation modules. The definition of product requirements and product specifications are a key points in the design process. ${ }^{10}$

The research of requirements and features of the objective group is a required period to develop products user-oriented. In the case of elderly, to have a great limitation of their capacities is essential to study how change depending on age, gender and geographic zone and where are the points of the inflection of such variability, this is where the application of the Universal design principles to general measures and solutions can remove barriers to participation in social life. Finally to emphasize that the application of design and the ergonomics to improvement of the spaces (furniture, everyday objects, technical aids), make safe habits, preventive behavior will allow to elderly and people with disabilities, to get older in their own context, improving their quality of life instead of requiring several people attending their family, or going to live in retirement spaces to satisfy their basic needs of the life. At the same time helps to reduce the dangers in the daily activities that carry disabilities, the fastest evolution of the disability and the fragility, and exalt the feelings of autonomy, wellness and safety reducing the costs in health care.

\section{Conclusion}

From the academy we must raise awareness to the future professional of the social-demographic changes that has the world. Their main challenge is aging of the global population and its close context. This factor is important because as they grow older, they need products and services according to their Physical-mental features that help them to do their daily activities and not be excluded from society. It is necessary to build strategies that plan to be basis for the Colombian gerontolgical design, these design strategies should be developed from sustainable, emotional, universal and inclusive design, also an in-depth study of the Colombian elderly.

\section{Acknowledgments}

None.

\section{Conflict of interest}

The author declares that there is no conflict of interest.

\section{References}

1. Organización Mundial de la Salud OMS. Informe Mundial sobre el envejecimiento y la salud. 2015.

2. Harper GJ, Crews DE. Aging, senescence and human variation. 2000.

3. Fabrycky WJ. Designing for the life cycle. Mechanical Engineering. 1987.

4. Papanek V. Diseñar para el mundo real. Ecología humana y cambio social. Blume Ediciones; 1977.

5. Gamonal R. La disciplina del diseño desde la perspectiva de las ciencias sociales. Revista prisma social. 2011;(7):1-19.

6. Krassoievitch M. Psicoterapia geriátrica. México: Fondo de Cultura y Economía; 1998.

7. Kirkwood T. Mechanisms of Ageing in Epidemiology in Old Age. London: BMJ Publishing Group; 1996.

8. Parra, Marujo. Gerontodesign: a marca de água do de- sign, do design ergonómico, da marca ou das marcas branca. 2006.

9. Harper S. La capacidad de las instituciones de seguridad social y de asistencia médica para adaptarse a un mundo que envejece. Revista Internacional de Seguridad Social. 2010;63(3-4):196-218.

10. Floréz Carmen Elisa, Villar, Leonardo. El proceso de envejecimiento de la población en Colombia. Bogotá: Fundación Saldarriaga Concha; 2015. 